\title{
Technical and Field Evaluation of Tractor Operated Frontal Pre-pruner for Kinnow Mandarin (Citrus reticulata) and Guava (Myrtaceae) Orchard
}

\author{
Manjeet Singh $^{1}$, Rupinder Chandel $^{1} \&$ Surinder Singh Thakur ${ }^{1}$ \\ ${ }^{1}$ Department of Farm Machinery and Power Engineering, Punjab Agrciultural University, Ludhiana, India \\ Correspondence: Rupinder Chandel, Department of Farm Machinery and Power Engineering, Punjab \\ Agrciultural University, Ludhiana 141004, India. E-mail: rupinder26@gmail.com
}

Received: January 19, 2021

Accepted: February 18, $2021 \quad$ Online Published: March 15, 2021

doi:10.5539/jas.v13n4p173

URL: https://doi.org/10.5539/jas.v13n4p173

\begin{abstract}
Fruit tree pruning is the cutting and removing of selected parts of a fruit tree. It spans through quite a number of horticultural techniques. Pruning includes cutting branches back, sometimes removing smaller limbs entirely and more so the removal of young shoots, buds and leaves. Established orchard practice of both organic and nonorganic types typically includes pruning. Pruning can control growth, remove dead or diseased wood, and stimulate the formation of flowers and fruit buds. Pruning and training young trees improves their later productivity and longevity and can also prevent later injury from weak crotches or forks (where a tree trunk splits into two or more branches) that break from the weight of fruit, snow, or ice on the branches. However, the efficiency of pruning methods is also important. Manual pruning has constraints like lower field Capacity and incomplete pruning in case of tall trees. Therefore, a tractor operated 1-row frontal pre-pruner with electro hydraulic control was tested for Kinnow Mandarin and Guava orchards. The time involved for top and side pruning was 23.30 and $46.80 \mathrm{~min} /$ acre, respectively and there was $99.32-99.38 \%$ saving in time as compared to manual pruning.
\end{abstract}

Keywords: hydraulic, vertical, disc, horizontal, automatic, 1-row, Kinnow Mandarin, Guava, pre-pruner, top pruning, side pruning

\section{Introcution}

Mandarin orange (Citrus reticulata) is the most common citrus fruits grown in India. It occupies nearly $40 \%$ of the total area under citrus cultivation in India. The most important commercial citrus species in India are the mandarin (Citrus reticulata), sweet orange (Citrus sinensis) and lime lemon (Citrus limon) sharing 41, 23 and $23 \%$, respectively of all citrus fruits produced in the country with an area of $0.428,0.185,0.286$ million ha and production rate of 5.1, 3.27 and 3.15 million metric tons, respectively (Anonymous, 2018). Citrus (Citrus sp., Rutaceae) is cultivated in the states of Maharashtra, Andhra Pradesh, Punjab, Himachal Pradesh, Uttar Pradesh, Madhya Pradesh, Karnataka, Jammu and Kashmir, Orissa, Gujarat, Assam, Meghalaya, Rajasthan, Sikkim and Tamil Nadu. It is an evergreen medium to tall erected tree. It grows to a maximum height of $25 \mathrm{~m}$ (Anonymous, 2020a). In India, Guava (Psidium guajava, Myrtaceae) is successfully grown in Uttar Pradesh, Bihar, Madhya Pradesh, Maharashtra, West Bengal, Orissa and Tripura. Uttar Pradesh is considered as the most important guava producing state in India, and the Allahabad-Varanasi region has the reputation of growing the best quality guava in the country as well as in the world. It is a hardy and tall tree with height of more than $2.5 \mathrm{~m}$ (Anonymous, 2020b). In most developing countries, manual pruning are used whereas in developed countries mechanical pruner are used. Pruning is at the heart of arboriculture, one of the most important services arborists provide (Clark \& Matheny, 2010). In the next future it is expected that greater use of wireless and lightweight equipment will be done to assess worker exposure to musculoskeletal disorders not only in pruning but in all farming operations (Elio et al., 2014). The results suggested that maintaining a live crown ratio of 55\% would minimize effects of pruning on diameter growth. The effect of severe pruning on diameter increment was greater for subdominant trees than for dominant stems (Neilsen \& Pinkard, 2011). In economic terms, if the rows are $400 \mathrm{~m}$ long, then the surface area suitable for mechanical pruning is 10 to 11 ha for all three varieties. There was no visible damage to the fruit branches with the mechanical pruner, but some damage occurred to wires with a diameter of less than $1.8 \mathrm{~mm}$ (Gambella \& Sartori, 2014). Canopy management system labour operation cost 
estimates indicated a labour saving of $62 \%$ and $80 \%$ with mechanical prepruning with hand shoot thinning (MPDHT) and mechanical box-pruning with mechanical shoot thinning (MPDMT) treatments, respectively when compared with hand pruning (HP) for 'Cabernet sauvignon' grape (Vitis vinifera). All treatments had similar yield, total soluble solids (TSS), juice $\mathrm{pH}$, and titratable acidity (TA), Berry skin total phenolics, anthocyanins, and tannins at harvest. All treatments tested were within acceptable Ravaz index limits of 5 to 10 $\mathrm{lb} / \mathrm{lb}$. However, only MPDMT treatment reached a near optimum leaf area to fruit ratio of $1.2 \mathrm{~m}^{2} \mathrm{~kg}^{-1}$ and pruning weight of $1.0 \mathrm{~kg} \mathrm{~m}^{-1}$ for warm climate viticulture (Kurtural et al., 2012). Sanding and pruning are two practices used in the cranberry (Vaccinium macrocarpon) industry for vine management and yield stimulation. Cumulative yield and net returns were higher in light severity treatments compared to those in the moderate and heavy treatments. Moderate and heavy sanding treatments were associated with lower yields and net returns than those for the untreated controls (Suhayda et al., 2009). Chancellor cited in Persson (1987), Kempe (1967) and Johnston (1968a and 1968b) also reported that the cutting force required when pruning a range of herbaceous (Phleum pratense) and woody (Picea glauca, Pinus resinosa, Pinus banksiana, Pinus taeda, Pinus radiata, Abies balsamea) up to $18 \mathrm{~cm}$ thick materials was greatly affected by the knife thickness. In some cases, doubling the knife thickness resulted in 50\% increase in the cutting force. Mattson and Sturos (1996) on the other hand, found that knife thickness did not affect cutting force required to shear sugar maple (Acer sacharum) branches. This may have been due to lower cutting speeds $(>600 \mathrm{~mm} / \mathrm{sec}$ compared with $<10 \mathrm{~mm} / \mathrm{sec})$ in the earlier study. Little agreement exists about the effect of cutting edge angle $(A)$ on force and energy requirements. Kempe (1967) reported that a $45^{\circ}$ cutting edge angle require 20 to $30 \%$ less force to shear spruce logs than what was needed with a $60^{\circ}$ angle. Mattson and Sturos (1996) found that reducing the cutting edge angle $(A)$ from $45^{\circ}$ to $30^{\circ}$ resulted in a 55\% reduction in peak force necessary for shearing sugar maple branches. Koch (1971) reported that a $9.5 \mathrm{~mm}$ thick blade with a $22.5^{\circ}$ cutting edge required $45 \%$ less total energy and $25 \%$ less peak force for shearing $130 \mathrm{~mm}$ diameter Southern Pine logs than was required when using a $45^{\circ}$ cutting edge $(A)$. The counteredge angle has also been shown to affect peak force requirements. Chancellor (1957) stated that a "fine" counteredge requires approximately $25 \%$ less force than a "blunt" counteredge. Kempe (1967) reported that knives with recessed sides required $20 \%$ less peak force for the same cutting edge angle and thickness than parallel-sided knives. Koch (1971) found that tapered knives with a thin root also required less force. Koch (1971) and Johnston (1968b) both commented that small reductions in the necessary force could be achieved if the friction co-efficient between the blade and the wood was lowered. Greasing the blade has been found to have no appreciable effect but teflon coating of the blade surface is effective. The manner in which the force is applied has also been shown to have an effect. Mattson and Sturos (1996) demonstrated that an oblique cutting angle ( $\beta$ ) requires greater peak force. They also examined the effect of cutting speed $(600 \mathrm{vs} 1100 \mathrm{~mm} / \mathrm{sec})$ on required force but found no significant difference at these high speeds. In summary, there performance may possibly be improved by tuning such design features as knife thickness, cutting edge angle $(A)$, knife shape, knife friction, oblique cutting angle (13) and counteredge angle. Total energy and peak force required for cutting radiate pine and Douglas-fir branches were measured. Branch sizes ranged from 9 to $65 \mathrm{~mm}$. Under one set of standard conditions some shears required over 50\% more energy and peak force than others. Douglas-fir required more energy and force than radiate pine. Total energy and force requirements tend to increase with cutting edge angle and with blade thickness (Crossland et al., 1997). The selection of pruner machine is also dependent on type of orchard. In general intensive/high density orchards (HD system) are characterized by densities between 250 and 700 trees per ha, super-high-density systems (SHD system) orchards can present densities over 1500 trees/ha (the hedgerow system). The average full yield in high density systems ranges between $6000-10000 \mathrm{~kg} / \mathrm{ha}$ for rainfed and irrigated orchards. However the economic life of the SHD is shorter (around 15 years, while in intensive system it can be more than 30 years) due to the lack of space and the competition among trees for light and ventilation inside the canopies (Freixa et al., 2011). Intensive tree orchard with narrow tree canopy or even 2D planar fruiting wall would be suitable for fully autonomous pruning system in the future. With the adoption of intensive tree architecture as well as the improvement of cutting end-effector, tree branch identification and reconstruction, it is very promising to have a robotic pruning system for tree fruit crops (He \& Schupp, 2018). A remote operated system may be an operating alternative for pruning equipment although there are remote control systems developed in the United States, Canada and Israel (Castellanos et al., 2017). A study was done to determine the input requirements for both the hydraulic circuit and the mechanical pruner designs. Then a description of an adapted inter-axle carrier used for the experimental model of the hop mechanical pruner and of the effected field measurement follows, along with interpretation of the measured data. These data are depicted in clearly arranged graphs showing the dependency of pressure and hydraulic oil flow on the cutting disc rotational frequency (Hoffmann et al., 2015). 


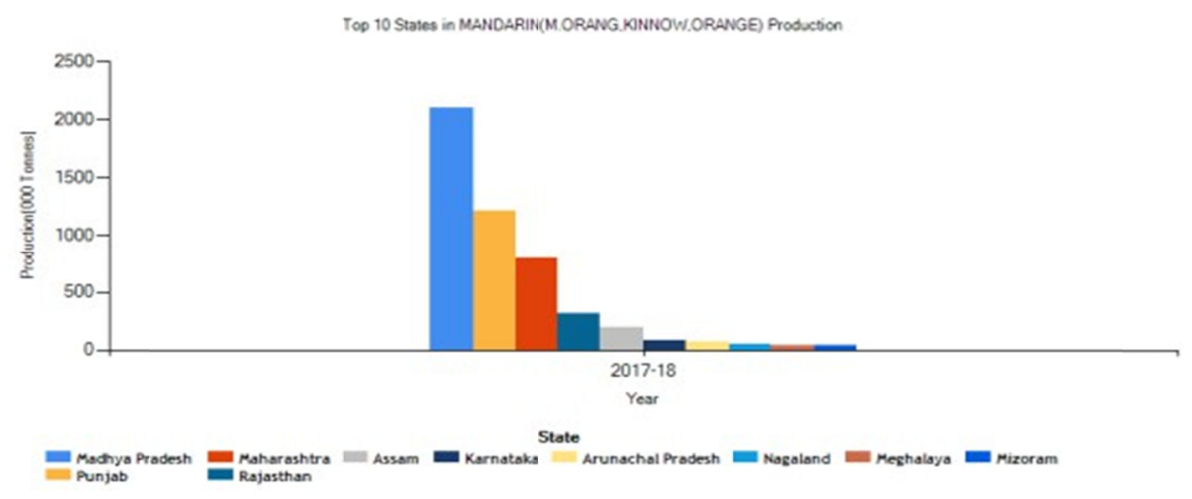

Figure 1. Major Mandarin producing states of India

Source: http://apeda.in/agriexchange/India\%20Production/India_Productions.aspx?cat=fruit\&hscode=1064

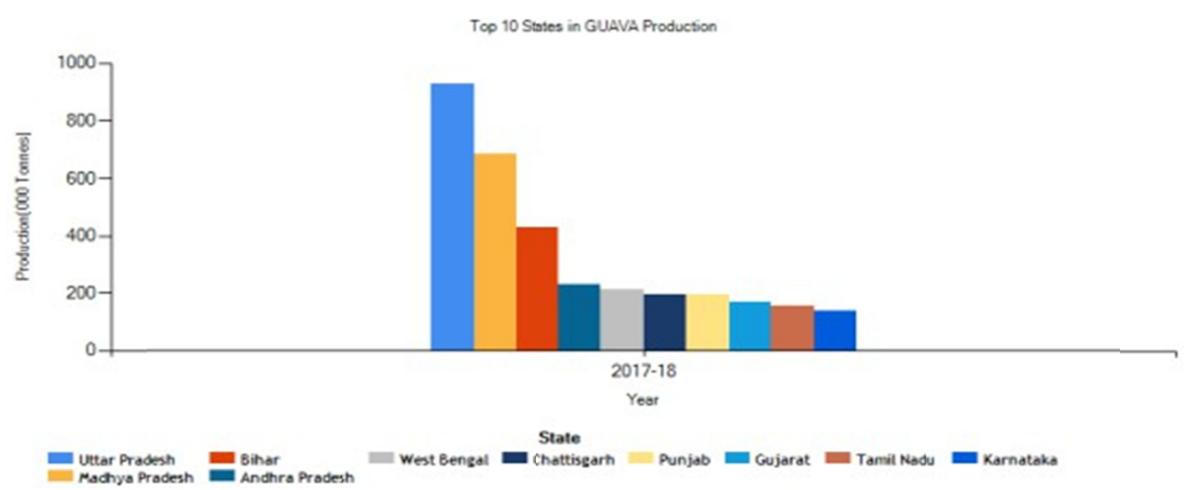

Figure 2. Major Guava producing states of India

Source: http://agriexchange.apeda.gov.in/India\%20Production/India_Productions.aspx?cat=fruit\&hscode=1046

Major Kinnow and Guava producing states in India are shown in Figures 1 and 2. The total area under Kinnow crop was around 53,045 ha which accounts for $60 \%$ of the total area under fruits in Punjab. The production of Kinnow was 1,246,821 MT. The area under Guava was 9142 ha with a production of 206106 MT (Thind \& Mahal, 2019). Manual pruning has constraints like lower field capacity and incomplete pruning in case of tall trees. Therefore a mechanical pruner can overcome both of these constraints. Therefore, a pre-pruner was tested for Kinnow and Guava orchards in Indian conditions.

\section{Material and Methods}

\subsection{Experimental Site Detail}

In 2017, a pre-pruner machine was operated at Kinnow and Guava orchards at Punjab Agricultural University, Ludhiana. The field evaluation of tractor operated pruner was done for Kinnow and Guava orchard at a spacing of $5 \mathrm{~m}$ by $7.5 \mathrm{~m}$ (plant spacing $\times$ row spacing) and height of Kinnow Mandarin and Guava tree varied from 3.66 $\mathrm{m}$ to $4.27 \mathrm{~m}$ with an average plant population of $275 \mathrm{ha}^{-1}$ (intensive/highdensity system). A view of Kinnow Mandarin orchard is shown in Figure 3. 


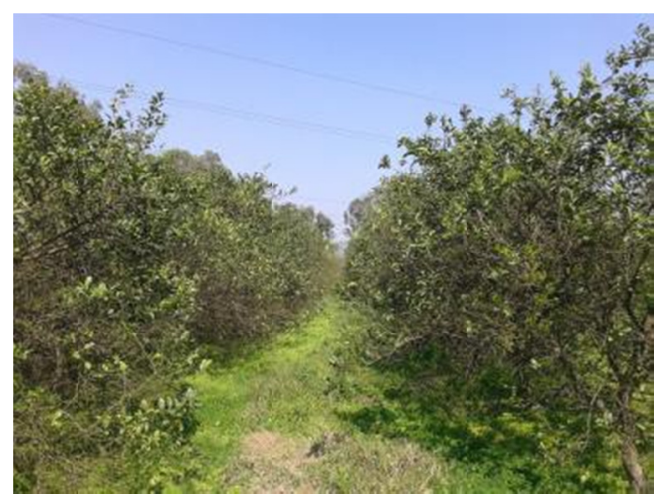

Figure 3. A view of Kinnow Mandarin orchard

\subsection{General Description of Pre-pruner}

Pre-pruner (Figure 4) machine is equipped as standard with hydraulic motors facilitated with safety system against stresses, cutting module (discs) of low maintenance without pulleys or belts, mechanical regulation of the angle of incidence of the cut, saws disks (Figure 5), inclination and hydraulic positioning of the cutting plane, hydraulic lifting, hydraulic lateral displacement, hydraulic power station and chiller. Its design is especially indicated for work in orchard traditional crops where the space between plants is reduced. Saw blades are 600 $\mathrm{mm}$ in diameter, with the availability of special discs for very thin branches or pruning in green. It requires a minimum power of $40 \mathrm{hp}$ tractor. The table is rotating to position the cutting module to the right or left of the tractor. It has a maximum cutting diameter up to $12 \mathrm{~cm}$ with a maximum cutting height in horizontal position of $4 \mathrm{~m}$ and minimum of $1.6 \mathrm{~m}$. The maximum height of vertical cut up is $7.15 \mathrm{~m}$ and $3.7 \mathrm{~m}$ down (pendulum). The machine high performance is due to its ease of operation and cutting positions with more than $250^{\circ}$ of travel in the position of the cutting module. On the PFS-5 (Reinforced orchard disc pruner compact) models the coupling to the tractor is front with number of hydraulic functions of $3+1$ and $4+1$. Discs RPM are $1650 \mathrm{rpm}$ but it also depend on the branches to be cut and the discs mounted on the machine. Different kind of discs can be used to cut different diameter of branches. The specifications of pre pruner are shown in Tables 1 and 2.

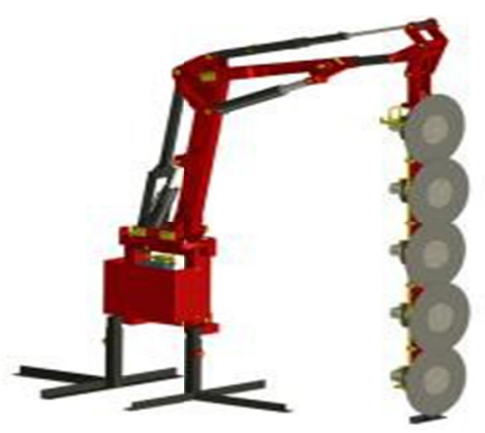

Figure 4. A view of pre-pruner
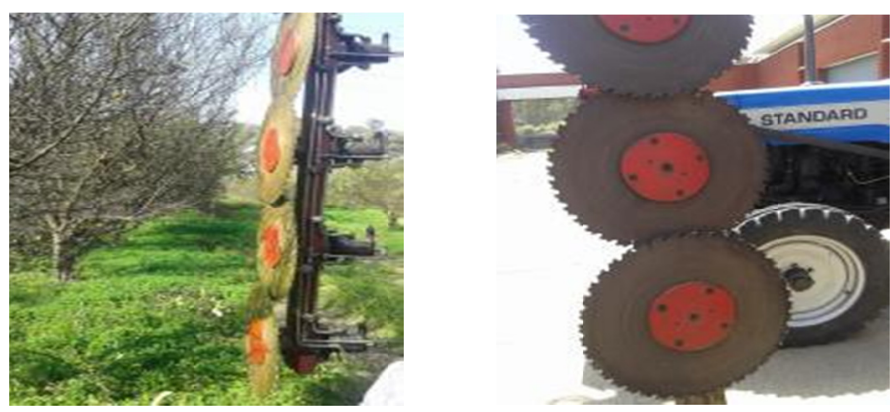

Figure 5. A view of cutting discs 
The pre-pruner is very high-tech fully hydraulic equipment and is equipped with individual hydraulic motors in each of the discs, therefore with total absence of pulleys or belts. Moreover its independent motor in each disc equipped with a safety valve and automatic reset in case of blocking, gives a great power of cut with a very reduced maintenance. It can be adapted to the front of the orchard's tractors allowing cutting both on the sides and at the top of the tree. Its design is especially indicated for work in orchard traditional crops. It is equipped with a turning frame which facilitates to work with the cutting bar positioned to the right or left of the tractor, being able to determine the cutting direction and the place of evacuation of the branches. Due to its high speed of turning, it gives a high cutting quality and correct evacuation of branches outside the tree. High quality of work and safety both in its handling as in the mechanical and hydraulic integrity of the same since it has individual systems of protection of the motors and rest of the hydraulic components.

\subsubsection{Main Technical Characteristics of Standard Equipment}

$\checkmark \quad$ Lift inclination and hydraulic extension.

$\checkmark \quad$ Electric controls in cabin.

$\checkmark \quad 1$ Motor + safety valve on each disc.

$\checkmark$ Hydraulic lifting.

$\checkmark$ Hydraulic sideshift.

$\checkmark$ Hydraulic inclination.

$\checkmark \quad$ Manual turning central frame (cutting left/right and branches discharge).

$\checkmark \quad$ Hardened steel 86 teeth-disc.

$\checkmark \quad$ 150L Hydraulic power unit with oil cooler and lateral counterweight box (C16).

$\checkmark \quad$ Power supply by independent hydraulicpower station to tdf.

$\checkmark \quad$ Front coupling to tractor. $\checkmark \quad$ Reverse hydraulic device of the cutting module. Other cutting heights on demand.

$\checkmark \quad$ Additional modules for cutting skirts.

$\checkmark$ Special module for pruning on the sides of the tree.

$\checkmark \quad$ Electronic speed control of the discs (Figure 5) in both directions.

$\checkmark \quad$ Integrated automatic control of cutting functions with programming in work position memories.

$\checkmark \quad$ Different types of cutting discs.

$\checkmark$ Safety system with automatic reset.

Storage foot includes:

$\checkmark$ Adaptable standard plate to tractor (frontal).

$\checkmark \quad$ Lateral support rods.

The tilt adjustment of the disc module is by electric control installed in a cab (Figures 6, 7 and 8), and has a mechanical adjustment of the angle of incidence. It is a very high-tech integral hydraulic drive machine. The standard dimensions of linkages of pre-pruner machine in various positions are shown in Figure 9.

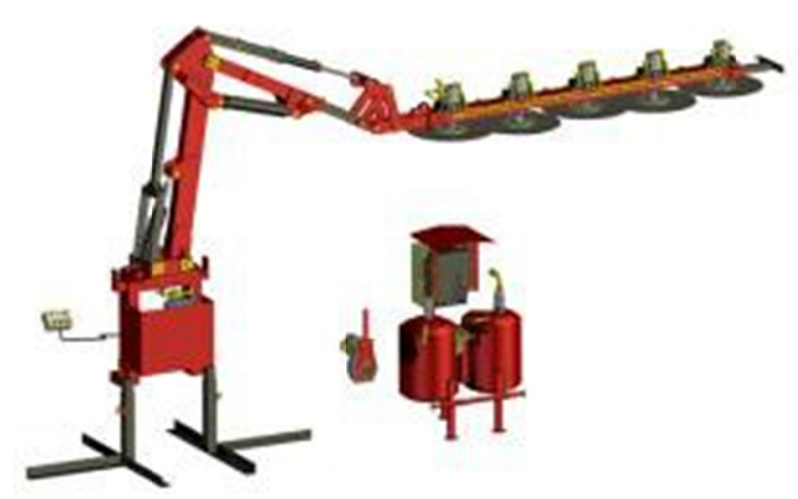

Figure 6. A Schematic view of various components of pre-pruner 

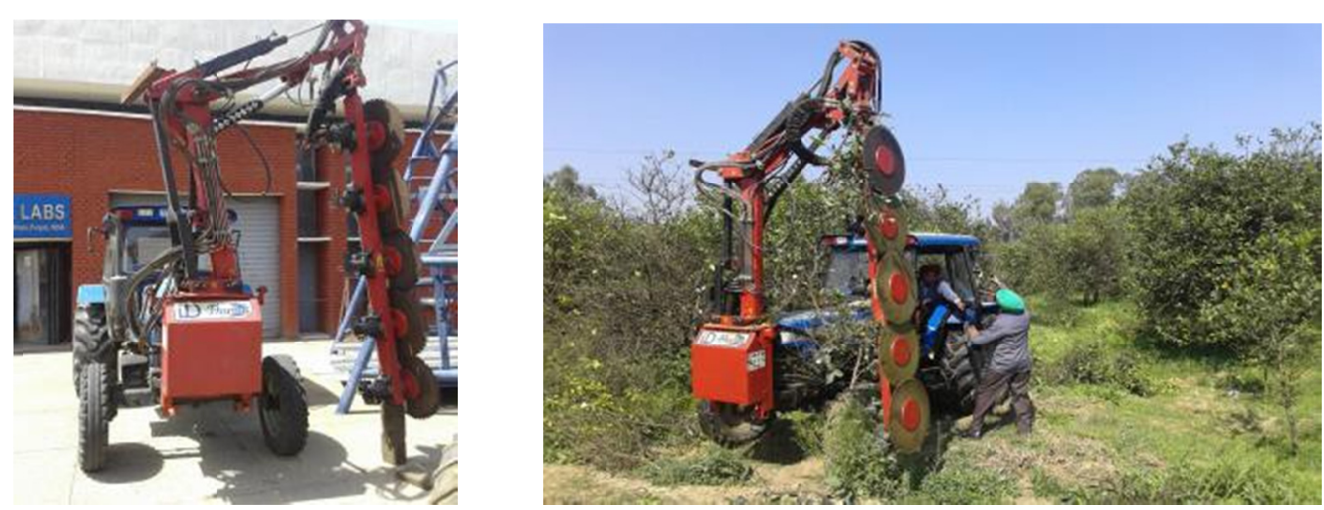

Figure 7. A view of tractor operated pre-pruner lab and field experiment

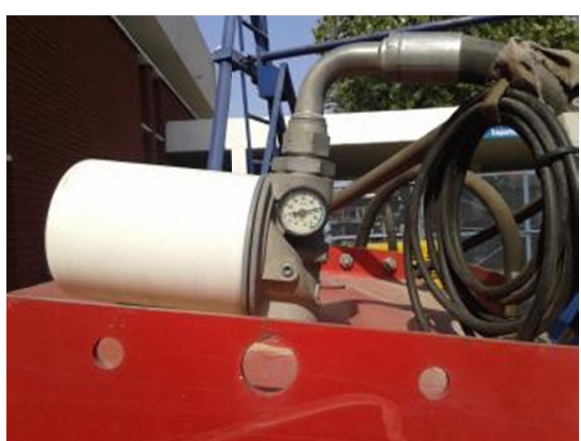

Figure 8. Pressure gauge for checking hydraulic oil pressure
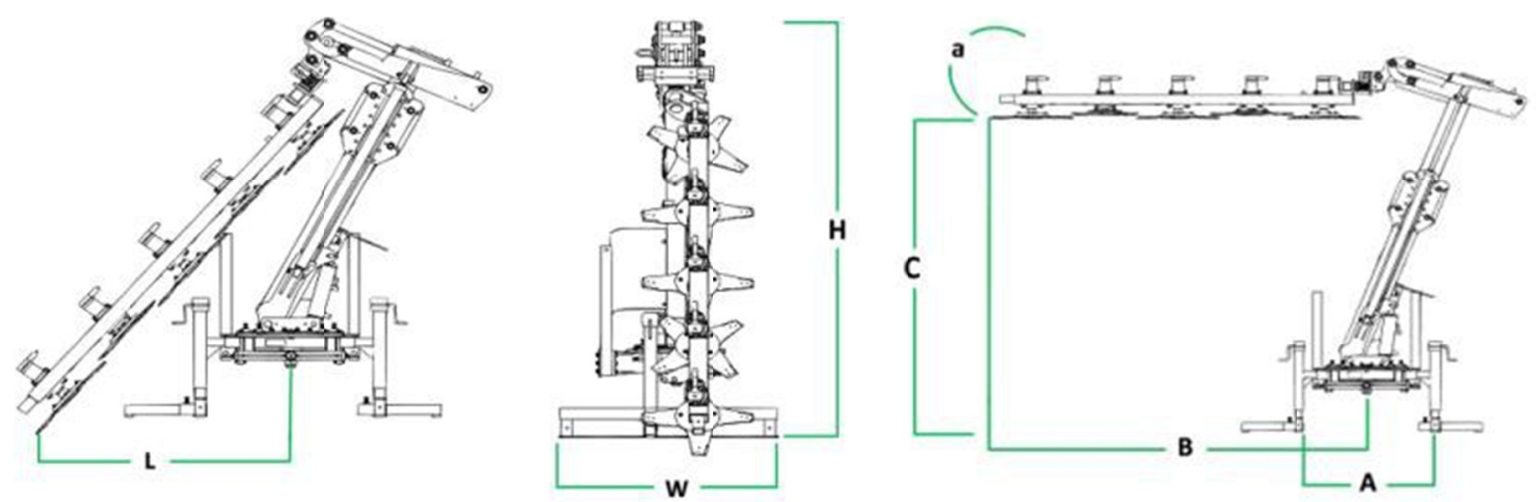

Figure 9. Various linkage dimensions of pre-pruner 
Table 1. Various technical specifications of pre-pruner

\begin{tabular}{|c|c|c|}
\hline Particulars & Symbols & Detail \\
\hline Tractor HP required & & $\geq 44.76 \mathrm{kw}$ \\
\hline $\begin{array}{l}\text { Battery power and current required to operate distributor } \\
\text { (driving various hydraulic mototrs) }\end{array}$ & & $12 \mathrm{~V}, 6 \mathrm{~A}$ \\
\hline Switches for horizontal positioning of pre-pruner & & One \\
\hline Switches for multiple positioning in horizontal mode & & Three \\
\hline Switches for vertical positioning of pre-pruner & & One \\
\hline Switches for multiple positioning in horizontal mode & & Three \\
\hline Model & & PFS-V5XX-2750, compact XXL frontal pre-pruner \\
\hline Type & & Frontal pre-pruner \\
\hline Movement & & Cut, lifting movement, tilting module \\
\hline Diameter discs $\mathrm{N} / \mathrm{mm}$ & & $5, \phi 600 \mathrm{~mm}$ (40 toothed) thickness of disc- $3 \mathrm{~mm}$ \\
\hline Cutting disc tours/minute or revolutions per minute (rpm) & & $1650 \mathrm{t} / \mathrm{m}$ \\
\hline Cutting length & & $2750 \mathrm{~mm}$ \\
\hline Hydraulic functions & & 4 \\
\hline Movements $\mathrm{N}^{\circ}$ & 1) & 3 \\
\hline Weight, $\mathrm{kg}$ & & 920 \\
\hline $\mathrm{A}, \mathrm{mm}$ & & 770 \\
\hline $\mathrm{B}, \mathrm{mm}$ & & $\operatorname{Min} 2700, \operatorname{Max} 4150$ \\
\hline $\mathrm{C}, \mathrm{mm}$ & & Min 2700, Max 4200 \\
\hline $\mathrm{H}, \mathrm{mm}$ & & 2900 \\
\hline $\mathrm{W}, \mathrm{mm}$ & & 1170 \\
\hline $\mathrm{L}, \mathrm{mm}$ & & 2600 \\
\hline
\end{tabular}

Table 2. Specifications of hydraulic motors and hydraulic system

\begin{tabular}{ll}
\hline Particulars & Details \\
\hline Operating Temeperature & -20 to $+110\left[{ }^{\circ} \mathrm{C}\right]$ \\
Max Continuous pressure & $200[\mathrm{bar}]-2901[\mathrm{psi}]$ \\
Required contamination class & ISO4406 20/18/15 (NAS1638-9) or better \\
Max torque & $140[\mathrm{Nm}]$ \\
Pressure peak drain & $25[\mathrm{bar}]-362.5[\mathrm{psi}]$ \\
Valve setting & $170[\mathrm{bar}]-2466[\mathrm{psi}]$ \\
\hline
\end{tabular}

To make the machine functional it was necessary to develop the control box indigenously. Material required to develop control box included switches, switch boards, ICB, hydraulic pipes, wires etc and this indigenous control box was designed and developed with the support of local industry. Electro hydraulic control has been made by electro valves connected through a control box.

\subsection{Estimation of Field Capacity}

The effective field capacity was determined by measuring all the time elements involved while harvesting. The total time was categorized into the productive and non-productive time. The productive time is the actual time used for harvesting the grains while the non-productive time consisted of the turning time, repair and adjustment time and other time losses. The area covered divided by the total time gave the effective field capacity. The effective field capacity of combine was calculated using the following formula (Kepner et al., 1978):

$$
C=\frac{S W}{10} \times \frac{E_{f}}{100}
$$

where, $C$ : effective field capacity, ha $\mathrm{h}^{-1} ; S$ : speed of travel, $\mathrm{km} \mathrm{h}^{-1} ; W$ : rated width of implement, $\mathrm{m} ; E_{f}$ : Field efficiency, in percent.

$$
E_{f}=100 \times \frac{T_{0}}{T_{e}+T_{h}+T_{a}}
$$


where, $T_{0}$ : theoretical time per hectare (per acre); $T_{e}$ : effective operating time $=T_{0} \times 100 / K$; $K$ : percent of implement width actually utilized; $T_{h}$ : time lost per acre due to interruptions that are not proportional to area. At least part of $T_{h}$ usually tends to be proportional to $T_{e}$; $T_{a}$ : time lost per acre due to interruptions that tend to be proportional to area.

\subsection{Estimation of Fuel Consumption}

Before starting the test, the engine's fuel tank was completely filled. The quantity of fuel required to fill the tank after harvesting the test field was measured using a $1 l$ graduated cylinder. Thus, the fuel consumed during the test was determined.

$$
\mathrm{F}=\mathrm{L} / \mathrm{A}
$$

where, $F$ is the fuel consumption in $1 \mathrm{ha}^{-1} ; A$ is the area harvested in ha; and $\mathrm{L}$ is the quantity of fuel required to fill the tank after harvesting the test field in $l$.

\subsection{Economics}

For economics calculations labour cost, diesel cost, repair cost etc. were considered. The economics was worked out for comparing the tractor operated pre-pruner savings as compared to manual pruning operation.

\subsection{Statistical Analysis}

The Two way Anova was used for statistical analysis of data. The two-factor Anova with replication was applied on field data.

\section{Results and Discussions}

Field evaluation of pre-pruning machine was done for Kinnow at new orchard, PAU, Ludhiana, 2017. Other orchard specifications and operational parameters are shown in Table 3.
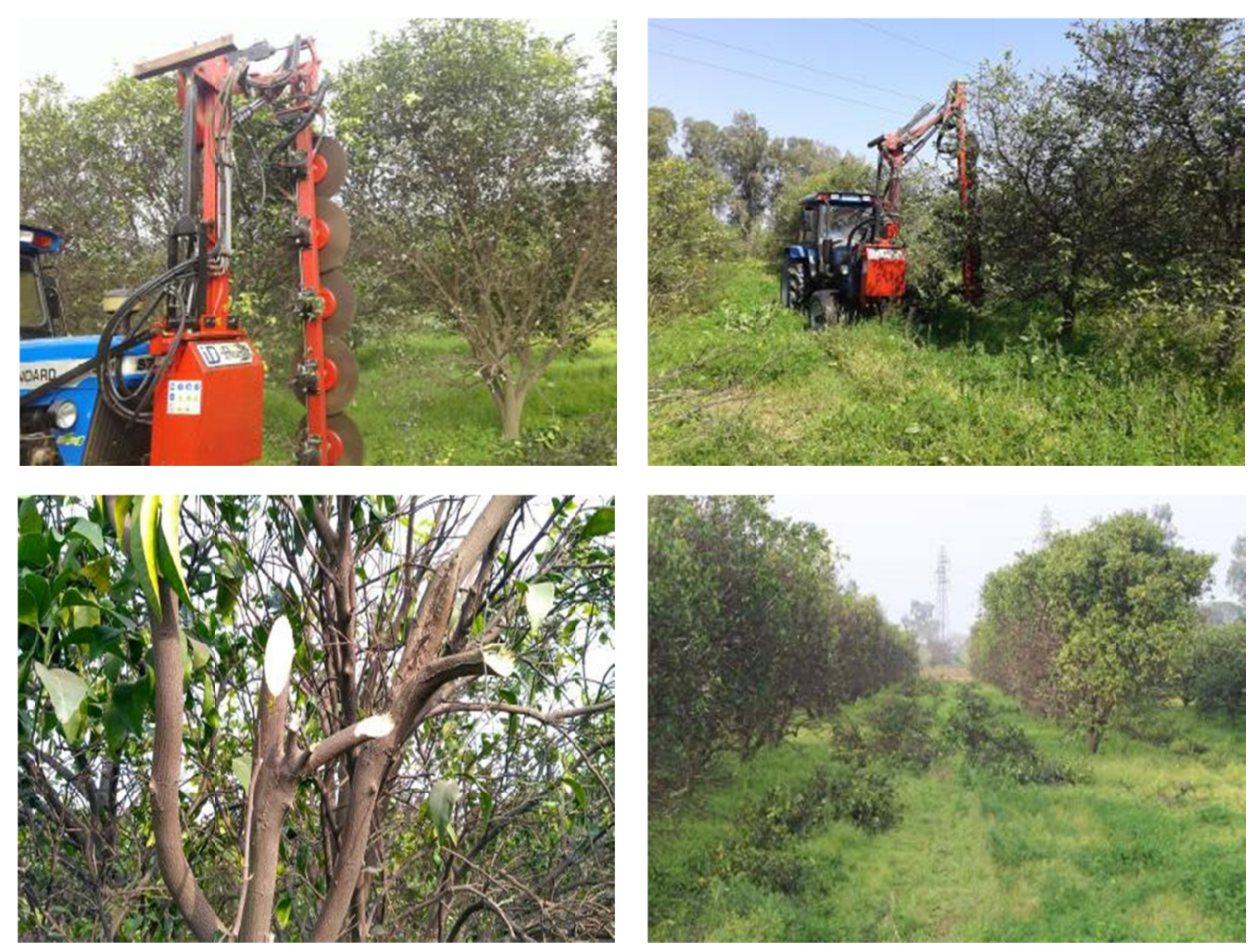

Figure 10. Sequential view of tractor operated pre-pruner in vertical cutting position and view of cut branches 
Table 3. Orchard specifications and operational parameters of pruner for Kinnow Mandarin and Guava orchard

\begin{tabular}{ll}
\hline Particulars & Range/Mean \\
\hline Average forward speed of Pruner, $\mathrm{Km} \mathrm{h}^{-1}$ & 2.73 \\
Fuel Consumption, $1 \mathrm{~h}^{-1}$ & $5.0-6.0$ \\
Canopy width between pruning, $\mathrm{m}$ & 2.52 \\
Canopy width after pruning, $\mathrm{m}$ & 1.94 \\
Canopy height before pruning, $\mathrm{m}$ & 4.11 \\
Canopy height after pruning, $\mathrm{m}$ & 3.00 \\
Uncut lower branch height, cm & $63-78$ \\
Cut branch diameter/thickness, mm & $5-25$ \\
\hline
\end{tabular}

The field layout was prepared prior to each operation in orchard for maximizing field efficiency and minimizing time lost in turnings. The time of travel for each straight row and time involved in turnings were recorded for each orchard field capacity calculations. The speed of cutting discs and inclination of cutting bar was controlled by electronic panel, distributor and hydraulic mototrs provided for each saw blade.

The machine was operated on side and top and side of Kinnow Mandarin and Gauava plants (Figures 10 and 11) and time of operation for both kinds was recorded and is shown in Table 4.
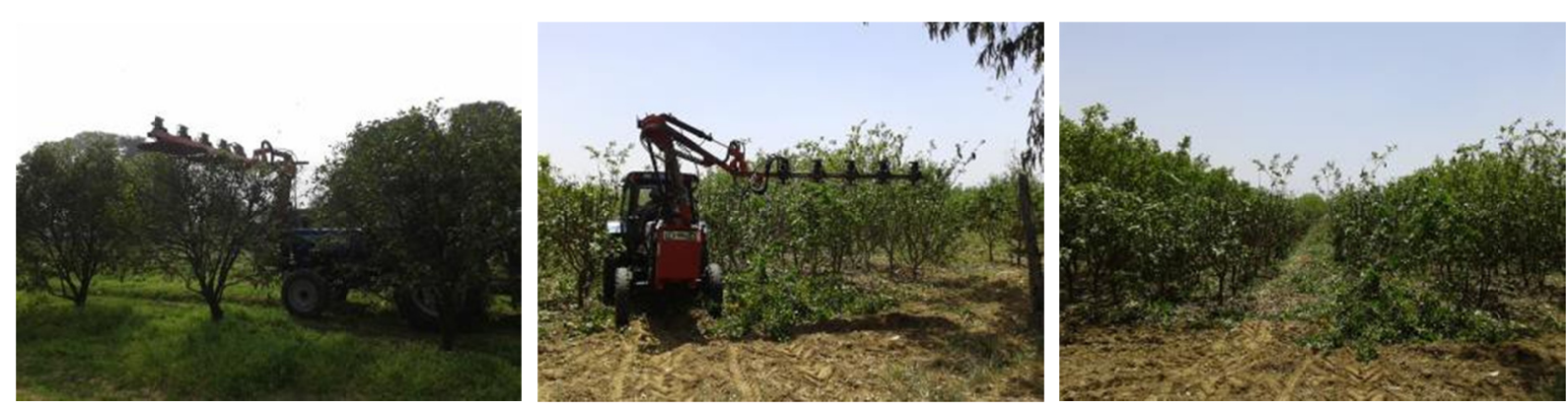

Figure 11. Top Pruning in Guava and Kinnow Mandarin orchard and view of cut branches in Guava orchards

The time involved in pruning for kinnow orchard was 40.86 and $23.30 \mathrm{~min} / \mathrm{acre}$ for side and top pruning. The pruning time involved per tree for side and top pruning was 19.46 seconds and 11.10 seconds respectively. The number of plants in one row was 21 .

Table 4. Mean time for side and top pruning of Kinnow Mandarin and Guava orchards

\begin{tabular}{lllllll}
\hline \multirow{2}{*}{ Method of pruning } & \multicolumn{2}{c}{ Mean time for pruning/tree } & & \multicolumn{2}{c}{ Mean time for pruning/acre } & \multirow{2}{*}{ Saving in time } \\
\cline { 2 - 3 } & Side & Top & & Side & Top & \\
\hline Tree Pruner & 19.46 Seconds & 11.10 seconds & & 40.86 min. & 23.30 min. & $99.32-99.38$ \\
Manual Pruning & $60-90 \mathrm{~min}$. & Not possible & & $126-189 \mathrm{~h}$ & Not possible & - \\
\hline
\end{tabular}

Table 5. Effect of pruning method on time of side pruning for a single tree and for an acre field (including turning time)

\begin{tabular}{|c|c|c|c|c|c|c|c|}
\hline Parameter & Method & $\mathrm{R}_{1}$ & $\mathbf{R}_{2}{ }^{\prime}$ & $\mathbf{R}_{\mathbf{3}}$ & $\mathbf{R}_{4}$ & $\mathbf{R}_{5}$ & Mean \\
\hline \multirow{2}{*}{ Time for pruning per tree, seconds } & Pre-pruner & 15.29 & 22.86 & 22.71 & 20.43 & 16.00 & 19.46 seconds \\
\hline & Manual pruning & 171.43 & 228.57 & 214.29 & 234.29 & 257.14 & 221.14 seconds \\
\hline \multirow{2}{*}{ Time for pruning per acre, min/acre } & Pre-pruner & 32.10 & 48.00 & 47.70 & 42.90 & 33.60 & 40.86 minutes \\
\hline & Manual pruning & 7560.00 & 8400.00 & 9600.00 & 10800.00 & 11340.00 & 9540.00 minutes \\
\hline
\end{tabular}


Table 6. Results of two factors Anova with replications

\begin{tabular}{lllllll}
\hline Source of variation & SS & df & MS & F & P-value & F crit \\
\hline Sample & 117632531.4 & 1 & 117632531.4 & 187.1728 & $3.01 \mathrm{E}-10$ & 4.493998 \\
Columns & 109050524.4 & 1 & 109050524.4 & 173.5174 & $5.27 \mathrm{E}-10$ & 4.493998 \\
Interaction & 108053313.6 & 1 & 108053313.6 & 171.9306 & $5.64 \mathrm{E}-10$ & 4.493998 \\
Within & 10055525.93 & 16 & 628470.3706 & & & \\
Total & 344791895.3 & 19 & & & & \\
\hline
\end{tabular}

Table 7. Time involved in top pruning with pre-pruner for single tree and for an acre field (including turning time)

\begin{tabular}{|c|c|c|c|c|c|c|c|c|c|}
\hline Parameter & Method & $\mathbf{R}_{1}$ & $\mathbf{R}_{2}$ & $\mathbf{R}_{3}$ & $\mathbf{R}_{4}$ & $\mathbf{R}_{5}$ & $\begin{array}{l}\text { Mean time } \\
\text { per row }\end{array}$ & $\begin{array}{l}\text { Mean time } \\
\text { per tree }\end{array}$ & $\begin{array}{l}\text { Mean time } \\
\text { per acre }\end{array}$ \\
\hline \multirow{2}{*}{$\begin{array}{l}\text { Time for pruning per tree, } \\
\text { seconds }\end{array}$} & Pre-pruner & 236 & 171 & 295 & 267 & 196 & 233 seconds & 11.10 seconds & - \\
\hline & Manual pruning & - & - & - & - & - & - & - & - \\
\hline \multirow{2}{*}{$\begin{array}{l}\text { Time for pruning per acre, } \\
\mathrm{min} / \mathrm{acre}\end{array}$} & Pre-pruner & 23.60 & 17.10 & 29.50 & 26.70 & 19.60 & - & - & 23.30 \\
\hline & Manual pruning & - & - & - & - & - & - & - & - \\
\hline
\end{tabular}

The saving of time for pre-pruner as compared to manual pruning varied between $99.32-99.38 \%$. For side pruning two sides were considered and for top pruning only one side was considered. The time for turning of pre-pruner was measured as 60 seconds and was added in both times involved in side pruning and top pruning. The effect of pre-pruner and manual pruning on pruning time per tree and pruning time per acre are shown in Table 5 and results of statistical analysis are shown in Table 6 . The data for time involved in top pruning of tree is shown in Table 7. The effect of pruning method was significant on time involved in side pruning per tree and per acre $(\mathrm{p}<0.05)$. Some authors, such as Kallsen (2005), compared several types and intensities of mechanical pruning, such as topping at several heights and some hand-pruning intensities, with non-pruning. He noticed that, in all cases, the higher the pruning intensity was, the lower the yield was, regardless of the type of pruning used. In the same way, Joubert et al. (2000), working in South Africa, tested the effect of light and severe prepruning followed up by hand pruning in 'Valencia'and 'Navel' oranges and 'Star Ruby' grapefruits. After three years'experimentation, they were able to confirm that all the systems tested produced a higher yield than the unpruned control, with the best choice being hedging with an inclination of $10-20^{\circ}$ combined with hand pruning once or twice a year. Pre-pruning in which a tilted plane is produced facilitates lighting of the bottom of the tree and also favours the concentration of fruits in the lower part of the tree, which makes manual harvesting easier. Spanish citrus farmers like to leave the trees with large skirts because this is a highly productive part of the tree. However, skirting tests performed with prepruners have shown that the overall production of the tree is not affected, while mechanical harvesting is facilitated, problems with soil fungus are reduced and tree microclimate is affected (El-Zeftawi, 1976; Morales et al., 2000; Sauls, 2008). Nowadays, mechanical pruning, either alone or combined with hand pruning, is used by some Spanish farmers. It is, however, not a technique that is widely accepted by growers, among other reasons due to a lack of experience. Pruning citrus trees must be a general canopy management strategy based on the understanding of specific pruning and regrowth management practices that must be combined with cost-effective methods adapted to each orchard period, growth, full production and old trees decline due to age and/or shading (A. J. Krajewski \& S. A. Krajewski, 2011). So economics part was also calculated for the pre-pruner operation keeping in view its future scope.

\section{Economics}

The economics calculation was also done for pre-pruner and manual pruning method. The operational cost for pre-pruner and manual pre-pruner were calculated taking into account their field capacities. The field capacity was calculated using all the time involved in pruning 


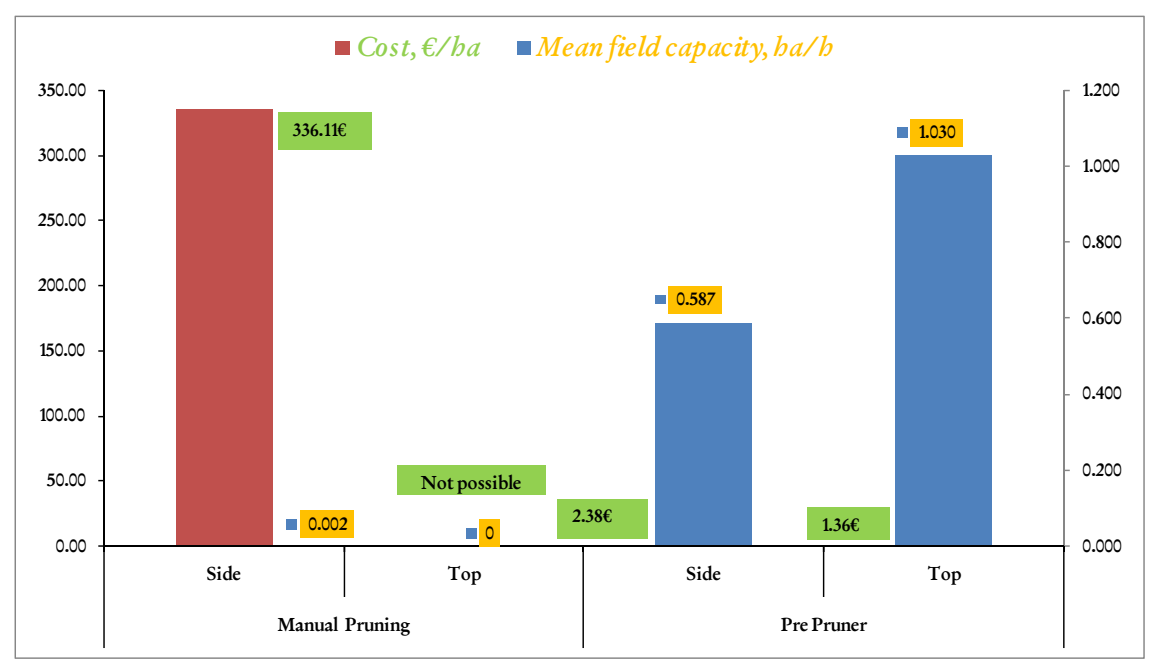

Figure 12. A graphical representation of field capacity and cost of pruning operation for pre-pruner and manual pruning operation for manual method

For pre-pruner machine time lost in turnings, breakdowns etc were taken into account. The labour cost $(0.61 € / \mathrm{h})$, diesel cost $(0.79 € / \mathrm{L})$, repair costs were considered for calculations. The cost of operation for side pruning operation for pre-pruner and manual pruning were calculated as $2.38 € /$ ha and $336.11 € /$ ha respectively (Figure $12 ; 1 €=82.19$ INR). The cost of top pruning for manual method was not worked out as it was not possible for this method. The cost of top pruning in case of pre-pruner was worked out as $1.36 € /$ ha. The saving in cost with pre-pruner machine for side pruning was $99.29 \%$ with added advantage of complete top pruning of tall fruit plants/orchards.

\section{Conclusions}

The mean field capacity of manual pruning was calculated as $0.002 \mathrm{ha} \mathrm{h}^{-1}$ for side pruning and for top pruning the manual efficiency was very low and unable to complete the pruning due to reach problem. Whereas in case of tractor operated pre-pruner the mean field capacity was higher for side and top pruning as $0.587 \mathrm{ha} \mathrm{h}^{-1}$ and $1.030 \mathrm{ha} \mathrm{h}^{-1}$ respectively along with benefits of efficient and complete pruning. Orchard planting geometry should be such as to facilitate easy, quick and balanced movement of tractor in between rows and at headlands, i.e., orchards should have minimum of ridges, undulation as well as weeds/grasses to avoid slippage of tractor during operation and for maximizing field capacity of machine. The irrigation planning of orchard should be done keeping in view the date of next pruning operation or should be well in advance before pruning operation so that during pruning field is in dry conditions this so to provide good traction condition for tractor during operation. The operator should be fully aware about controls of pre pruning machine and equipped with good driving skills which are very important for field operation and road movement of pre pruning machine.

Tractor with cabin should be preferred for pre pruning machine for safety of operator as during pruning of trees small wooden pieces may hit and cause injury to the tractor operator. For plants having height more than 10 feet high clearance tractor may be used for enhancing visibility of operator during field operation. The pruning of tree sides should be done before start of top pruning. The choking may occur in pre pruning machine for the case when machine is lowered to increase cutting height of top portion greater than overall height of cutting unit. Therefore cutting height for top portion should be selected accordingly.

\section{Before Starting Operation Operator Should Check These Points Daily}

$\checkmark \quad$ The oil level in the reservoir should be checked for marked level and if found less should be filled up to marked level first.

$\checkmark \quad$ Nuts of all the rotating blades and other units should be checked and tightened if needed.

$\checkmark \quad$ The free movement of pre pruning machine should be checked in all planes.

$\checkmark \quad$ The rotary blades should be checked by running them ideally.

$\checkmark \quad$ All the hose pipes should be checked for any leakage and if found should be repaired or replaced before operation. 
$\checkmark \quad$ The support system of should be checked thoroughly for any loose nuts and if found any should be tightened.

$\checkmark \quad$ The wearing of cutting discs also depend on the branches diameter but normally they need sharpening before starting a new season.

\section{Acknowledgements}

This research was funded and supported by the Department of Farm Machinery and Power Engineering, College of Agricultural Engineering, Punjab Agricultural University, Ludhiana, Punjab, India under the scheme called Establishment of Department of Farm Machinery and Power Engineering, Plan-17-B (PC-1062.2). The team acknowledges Cristina Castagnotto, Industrias David, S.L.U., Apdo. 6-30510 Yecla (Murcia) Spain for providing necessary technical data about pre pruner machine.

\section{References}

Anonymous. (2018). Retrieved from https://www.statista.com/statistics/1038920/india-production-of-citrusfruits-by-type

Anonymous. (2020a). Retrieved from http://nhb.gov.in/PDFViwer.aspx?enc=3ZOO8K5CzcdC/Yq6HcdIxAGNy Jr57hWR0xYb9YOVOQ4=

Anonymous. (2020b). Retrieved from http://nhb.gov.in/PDFViwer.aspx?enc=3ZOO8K5CzcdC/Yq6HcdIxEP0do TqzNQwV6rCyJkpaW4=

Castellanos, L. B., Simoni, R., Martins, D., \& Vieira, R. D. S. (2017). Tree Pruning in Electrical Network: Topic and Fundamentals in Machines and Robots (pp. 41-46). Actas de las IX Jornadas Argentinas de Robótica 15-17 de Noviembre, Córdoba, Argentina Articulo Cientifico Completo.

Clark, J. R., \& Matheny, N. (2010). The Research Foundation to Tree Pruning: A Review of the Literature. Clark and Matheny: The Research Foundation to Tree Pruning. Arboriculture \& Urban Forestry, 36(3), 110-120.

Crossland, P., Murphy, G., Martin, G., \& Dean, M. (1997). Energy and force requirements for six pruning shear designs. N.Z. Forestry.

Cunia, T. (1973). Dummy variables and some of their uses in regression analysis. Proceedings of IUFRO Seminar (pp. 1-146). Subject Group S4.02-Forest Resources Inventory, Nancy, France.

Elio, R., Davide, C., \& Venerando, R. (2014). A review of current studies to evaluate the effort of the hand of the pruner. Proceedings International Conference of Agricultural Engineering (pp. 1-8). Zurich, Switzerland.

El-Zeftawi, B. M. (1976). Response of 'Navel' orange trees to skirting. Sci Hortic, 5(1), 59-63. https://doi.org/ 10.1016/0304-4238(76)90023-6

Freixa, E., Gil, J. M., Tous, J., \& Hermoso, J. F. (2011). Comparative study of the economic viability of high and super-high-density olive orchards in Spain. Acta Horticulturae, 924, 247-254. https://doi.org/10.17660/ ActaHortic.2011.924.31

Gambella, F., \& Sartori, L. (2014). Comparison of mechanical and manual cane pruning operations on three varieties of grape (cabernet sauvignon, merlot, and prosecco) in Italy. Transactions of the ASABE, 57(3), $1-7$.

Hall, P. W., \& Mason, E. G. (1988). Pruners-are yours tuned to maxi-mum performance? (pp. 19-21). NZ Forestry.

He, L., \& Schupp, J. (2018). Sensing and Automation in Pruning of Apple Trees: A Review. Agronomy, 8(211), 1-18. https://doi.org/10.3390/agronomy8100211

Hoffmann, D., Heřmánek, P., Rybka, A., \& Jošt, B. (2015). Hydraulic Circuit of Mechanical Pruner Drive for Hops on Low Trellises. Scientia Agriculturae Bohemica, 46(3), 100-105. https://doi.org/10.1515/sab2015-0023

Johnston, J. S. (1968a). Experiments in crosscutting wood with shear blades. Forest Products Journal, 18(3), 85-89.

Johnston, J. S. (1968b). An experiment in shear-blade cutting of small logs. Pulp and Paper Magazine of Canada (pp. 77-82).

Joubert, F. J., Plessis, M. H., \& Stassen, P. J. C. (2000). Pruning strategies to alleviate overcrowding in higher density citrus orchards. J Appl Hort, 2(1), 1-5. https://doi.org/10.37855/jah.2000.v02i01.01 
Kallsen, C. E. (2005). Topping and manual pruning effects on the production of commercially valuable fruit in a midseason Navel Orange variety. HortTecnology, 15(2), 335-341. https://doi.org/10.21273/HORTTECH. 15.2.0335

Kempe, C. (1967). Forces and damage involved in the hydraulic shearing of wood. Studia Forestalia Suecica (No. 55, p. 33).

Kepner, R. A., Bainer, R., \& Barger, E. L. (1978). Principles of farm machinery (pp. 25-28). Westport: AVI Publishing Company.

Knowles, R. L. (1995). New Zealand experience with pruning radiata pine. In D. P. Hanley, C. D. Oliver, D. A. Mac-quire, D. G. Briggs, \& R. D. Fight (Eds.), Forest Pruning and Wood Quality of Western Noah American Conifers (Contribution No. 77, pp. 255-264). College of Forest Resources, University of Washington, Seattle, WA.

Koch, P. (1971). Force and work to shear green Southern Pine logs at slow speed. Forest Products Journal, 21(3), 21-26.

Krajewski, A. J., \& Krajewski, S. A. (2011). Canopy management of sweet orange, grapefruit, lemon, lime and mandarin trees in the tropics: Principles, practices and commercial experiences. Acta Hortic, 894, 65-76. https://doi.org/10.17660/ActaHortic.2011.894.5

Kurtural, S. K., Dervishian, G., \& Wample, R. L. (2012). Canopy Management Reduces Labor Costs and Maintains Fruit Composition in 'Cabernet Sauvignon' Grape Production. Horttechnology, 22(4), 509-516. https://doi.org/10.21273/HORTTECH.22.4.509

Mattson, J. A., \& Sturos, J. B. (1996). Reducing the forces required to delimb hardwoods (Research Paper NC-327, p. 8). USDA Forest Service, Noah Central Experiment Station. https://doi.org/10.2737/NC-RP-327

Morales, P., Davies, F. S., \& Littell, R. C. (2000). Pruning and skirting affect canopy microclimate, yields and fruit quality of 'Orlando' tangelo. HortScience, 35(1), 30-35. https://doi.org/10.21273/HORTSCI.35.1.30

Neilsen, W. A., \& Pinkard, E. A. (2011). Effects of green pruning on growth of Pinus radiate. Canadian Journal of Forest Research, 33(11), 2067-2073. https://doi.org/10.1139/x03-131

Persson, S. (1987). Mechanics of cutting plant material (ASAE Monograph No. 7, pp. 194-195).

Reutebuch, S. E. (1995). Douglas-fir pruning in New Zealand: What can be leamed? In D. P. Hanley, C. D. Oliver, D. A. Macquire, D. G. Briggs, \& R. D. Fight (Eds.), Forest Pruning and Wood Quality of Western North American Conifers (No. 77, pp. 265-278). College of Forest Resources, University of Washington, Seattle, WA.

Sauls, J. W. (2008). Citrus pruning. Texas citrus and subtropical fruits. Retrieved March 14, 2008, from http://aggie-horticulture.tamu.edu/citrus/pruning/L2308.htm

Suhayda, B., DeMoranville, C. J., Sandler, H. A., Autio, W. R., \& Heuvel, J. E. V. (2009). Sanding and Pruning Differentially Impact Canopy Characteristics, Yield, and Economic Returns in Cranberry. Horttechnology, 19(4), 796-802. https://doi.org/10.21273/HORTSCI.19.4.796

Thind, S. K., \& Mahal, J. S. (2019). Package of Practices for cultivation of fruits (p. 1). Punjab Agricultural University, Ludhiana.

\section{Copyrights}

Copyright for this article is retained by the author(s), with first publication rights granted to the journal.

This is an open-access article distributed under the terms and conditions of the Creative Commons Attribution license (http://creativecommons.org/licenses/by/4.0/). 